\title{
Microfinance and its Impact on Indonesian Small to Medium Size Enterprise Productivity for Development
}

\author{
Yosua Christanto* Ahmad Danu Prasetyo \\ School of Business and Management, Institut Teknologi Bandung, Indonesia
}

\begin{abstract}
Microfinance is one of the key aspects that help the development of MSME, and it also applies globally. In many previous studies, there is no coherence about the impact of microfinance on the development of MSME. We investigate the impact of microfinance on the development of MSME in Indonesia. Panel regression is the method that is utilized in this present study because the current data is in panel form which came from 32 provinces in Indonesia with the range of 2012-2014. Results indicated that there are two variables which are the number of microloans, HDI that significantly influence the development of MSME, microloans, and HDI are negatively affected. The conclusion reflected the public views of Indonesian regarding entrepreneurship \& MSME development. Entrepreneurship is viewed poorly by the public, society values working in cooperations are more valuable.The results of the research also indicated boundaries such as regulations, and views that obstructed the development of MSME in Indonesia.
\end{abstract}

Keywords: Microloans, Economy, Microfinance, MSME, Entrepreneurship

\section{Introduction}

Indonesia is one of the top developing countries in the Asian region. Significant economic growth followed by competent human resources has successfully created a new potential major economic player. World bank report 2016 mentioned the country and projected its success in the future. As the next major player, there are several improvements the country should make in order to maintain the positive momentum of growth. Badan Pusat Statistik (BPS) 2011- 2017 indicated that significant economic contributions are provided by SME or small-medium enterprise sector. The reports also indicated that $\mathrm{SME}$ is also a major source of employment and help reduce poverty in the country (OECD, 2004).

A major contributor to the establishment of MSME and SME comes from microfinancing activities. Microfinancing activities are the process of providing financial service to SME \& MSME in order to help them to grow. Conventional banks, venture capital, and investment banks are some of the parties that provided microfinance activities. Microfinance activities are popular in developing countries. It is proven that the process assisted the development of industry. It reforms investment in a more sociable way. The activities had also indirectly supported equal opportunity.

Indonesia MSME \& SME is currently underdeveloped. Despite significant numbers, it's export contribution is low. MSME \& SME sustainability is also low due to high default rates (Sutomo, 2007). Lack of basic financial access causes a slowdown in the sector. Strict regulations and unbankable conditions of both SME \& MSME create a negative obstacle in economic development. In order for both MSME \& SME to maintain a steady growth rate, it is important to maintain microfinance activities. Government is obliged to boosts microfinancing activities and create positive reforms. 
However, some research indicated that a controversy that existed in microfinance activities (Michael Troilo, 2013). Previous studies showed that different timelines, different locations, and method will influence the results of the research. Some of the researchers mention the changed that had happened in microfinance activities since its establishment. These changes cause different conclusions among researchers.

The objective of the research is to discover variables that influence development of MSME. The research is also meant to discover the true value and impact of microfinance in its change. It also provides additional information related to the present microfinance system in Indonesia and its impact. The research will provide additional insights related to MSME in Indonesia. The study will also provide recommendations that will support the development of MSME in a more efficient way.

\section{Literature Review}

With the established law of UU No.20 2008, it classifies and defines SME in Indonesia under two aspects which are the number of profit and asset value.

Enterprises are considered to be micro in size if its asset value is under fifty million rupiah and have generated a stable profit over the year that is of the value of three hundred million rupiahs. Enterprise is considered to be small in size if the asset value ranges above fifty million to five hundred million, and have generated profit in the range of three hundred million to two point five billion rupiahs. Enterprises are considered to be medium in size if its total asset value is worth from the range of above five hundred million rupiahs to ten billion rupiahs and had successfully generated profit that values from two point five billion up to fifty billion rupiahs. The rest of the enterprise is considered to be a big size business.

In Indonesia, SME and MSME are considered to be one of the most resilient and versatile sectors during bad times such as inflation (BI, 2015). During $1998 \& 2008$, are one of the times that showed the true power of MSME, and SME in Indonesia. In crisis big corporation collapses due to poor market activity, and large exposure of foreign debt, while small enterprises survive.

According to Otero (1999) microfinance is the provision of financial services to low-income clients, including the self-employed (Ledgerwood et al., 2013). Microfinance activities are related to funding activities, including savings and credit, insurance and payment services. By the general term, microfinance is an action to fund small-sized enterprises that are commonly used to sustain lives (Ledgerwood et al., 2013). The focus of microfinance activities is providing additional and cheap capital to small and medium-sized enterprises. Microfinance assisted the development of the newly formed business that is potential and will increase the economic development of a country. Microfinance activities objectives are to increase the number of medium and micro businesses in a country and expect that these funded companies will expand and grow, into bigger businesses that will create new jobs and improve the economy of a country.

Access to funds and financial services is one of the keys that will support, and maintain the development of SME. BPS Report 2016, there are multiple sources of funding with a different interest rate, and risk. The most common providers are microfinance institutions (MFI), government and stateowned banks, venture capitalists, personal wealth, etc.

The easiest access to funds with cheaper interest rates provided by MFI, and conventional banks. The government controls Interest rates, and it varies from country to country based on the different views of the government towards SME.

According to Ledgerwood et al. (2013) microfinance is used to assure that all people have access to financial services. It is essential for both economic development and helpful for the people themselves. Product microfinance became a favorite topic starting in the year of 1970. Muhammad Yunus through the Grameen Bank Bangladesh. He is the founder and director of the Grameen bank that pioneered the activities of microcredit. The first microcredit formed as small-sized loans that are provided for the poor without any collateral to hope that it will help them exit the poverty cycle. He discovers and creates a new way to bypass conventional lending by setting up the microfinance loan system. Grameen bank also developed into a more socially friendly company, and significantly impacted the lives of the poor.

Due to his discovery, and merit he receives various achievements and international awards which included Ramon Magsaysay Award, the World Food Prize, and the Sydney Peace Prize. The Grameen bank profited from providing loans to the people that are not creditworthy. The bank also 
revives the lifestyle of the people especially the poor. As the success story of the activity become, famous worldwide other developing countries such as Brazil, Peru, etc. started their microfinance products. With the advancement of technology and needs microfinance also adapt to the changes, it changes slowly, and it is designed to take larger market share and to improve security over these types of loans.

Lützenkirchen (2012) argue that SME is considered to be one of the most versatile industry due to its ability to thrive during the crisis. OECD (2004) Explains that most of the SMEs (Small Medium Enterprises) entered financial difficulty and expansion constraints, even bankruptcy due to the challenges in accessing loans and financial services in global banks. Funding has become the number one obstacle to the development of all sizes of enterprises.

Tambunan (2011) explains that SME also significantly influences the Indonesian business cycle. Based on the research it also explained that there are about more than $60 \%$ of the population work in the SME industry. Therefore it is important for the government to support microfinance activities.

Zhuang (2009) indicated that in most cases the poor did not have full access to financial services and had difficulties in financing their primary need of living thus causing them to live in the poverty cycle. The sequence is created due to the inaccessibility of financial services to the poor. During those days the poor were seen as a bad investment in the eyes of conventional banks, and therefore there is a massive restriction on the access of loans.

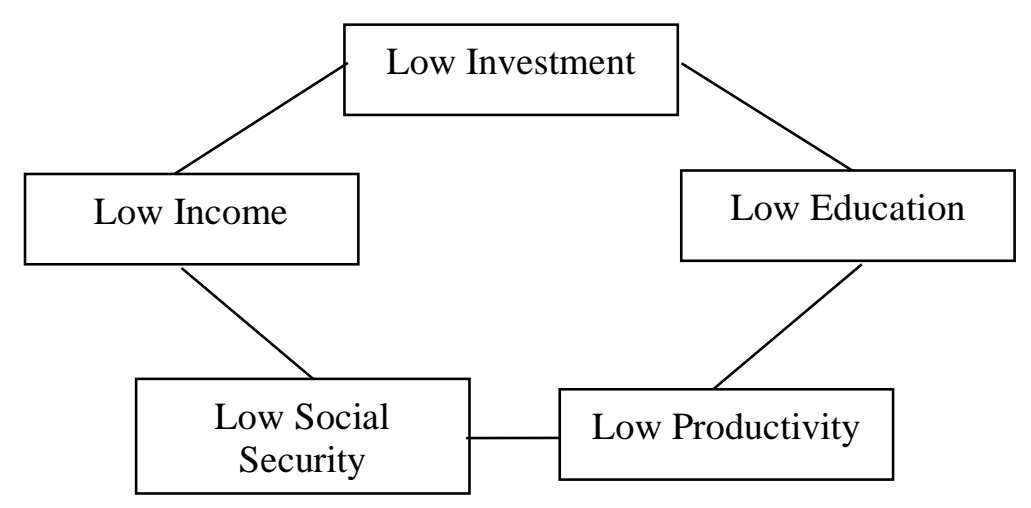

Figure 1. Poverty Sequence

There are six variables that will is utilized in the present research. The output of MSME will be the only dependent variable. Quantity of loan, regional GDP, HDI, unemployment number, inflation will be independent variables. Every variable except the quantity of loan is considered to be control variable. The focus of the current study analyze the influence of credit that is specially designed for MSME.

The present research utilizes five independent variables. The selected variables are considered to be endowment factors or factors that influence the productivity of MSME in Indonesia, this theory also becomes the primary reason the utilization of the variables.

There are two contradicting views over the product of microfinance. There is some research that had been previously conducted by professors, economists, and scholars. One side explains that microfinance is often inefficient and thus bring negative impacts towards society, economy, and it can also be considered as poverty trap. On the other side microfinance is explained to bring positive impacts and bringing new activities that are related with development of businesses and help the people that have difficulties accessing financial services.

Lützenkirchen (2012) concluded that microfinance will not cause an adverse impact on the development of the economy and it is not an effective way to decrease poverty. Microfinance has changed significantly and currently losing its ability to be more discipline in collecting payments of loans. And the research also shows that the objectives of microfinance itself started to deviate from its original goal to empower poor people.

Research indicates that MFI grows larger and larger. However, borrowers are riskier. Risk is not 
managed well and therefore burdens both sides who supplied the loans and the borrowers. Microfinance is getting more commercialized, and competitive business environment creates modern microfinance to be less effective. Bateman and Chang (2012) Research also added that microfinance is a very great poverty trap for the borrowers.

Reformation of the current microfinance system is necessary to preserve the original purpose and benefits of microfinance activities. The research from Babajide (2012) also concludes that access to microfinance does not influence the growth of small and medium enterprises. The research indicated that other firms' characteristics actually the primary factors that influence the development of MSME.

On the other hand, some studies from Ademola and Arogundade (2014); Pei-Wen et al. (2016); Sharma and Puri (2013); W and Ngugi (2014) have contradicting views with research from Babajide, (2012); Bateman and Chang (2012); Lützenkirchen (2012). The study was conducted from various geographical scope such as countries, regional, and towns by performing different methods such as ordinary least square of multiple linear regression, multiple linear regression, descriptive statistics and analysis, regression equation analysis. Data that was gathered also varies, however, every research concludes that the present microfinance system impacted positively in different aspects such as GDP, development of SME, and it also brought social consequences that are unmeasurable in quantitative values.

\section{Methodology}

Based on the selected variables there are five hypotheses that are being tested in the present research.

Hypothesis 1: Quantity of loans will positively influence the development of MSME.

Hypothesis 2: Regional HDI will positively influence the development of MSME.

Hypothesis 3: Unemployment quantity in each regional area will positively influence the development of MSME.

Hypothesis 4: Provincial GDP will indirectly, and positively influence the development of MSME because policies and regulations will be implemented and support it.

Hypothesis 5: The rate of inflation will negatively influence the development of MSME.

All the data used in this research are secondary data from Indonesia's official government sites such as Badan Pusat Statistik (BPS), Indonesian central bank websites. The data gathered from these locations included several things. The quantities of each province unemployment in Indonesia, output index of the Indonesian SME for each region (\%), and the number of microloans distributed for the SME for each province, provincial annual inflation rate, and rural HDI. All of the data gathered from these sites are then processed for further analysis.

The type of data used in the research is categorized as panel data which is a mixture of both time series data and cross-sectional data range of 2011-2014, of 32 provinces in Indonesia.

The present research utilizes a panel regression as a primary method to discover the major factors that will influence MSME development. Results from the processed number will be a good reference to create new policies and regulations that will assist the development of MSME.

The present research utilizes a panel form to maximize the value of observation, increase the objectivity of the research and provide more information compared to regular time series or crosssectional data. Panel regression is one of the most common statistical tools that is widely used by researchers (Gujarati and Porter, 2009). The panel is also utilized in the present research due to the data form, and the research objective.

The dependent variable (Y) in the present research is the development of MSME measured by the annual output of local MSME. Independent variables (X) consisted of multiple things such as the number of loans for MSME, HDI, inflation, the quantity of unemployment, and regional gross domestic product. The dependent variable is chosen based on the research objective to discover the impact of the development of MSME. The variables selected in the present research comes from combinations of past literature.

Execution of the panel regression model required it to select one approach out of three options that are available. Those three options are common, fixed, and random effect models. The present research data utilize panel form, therefore the available options are fixed and random effect. The only necessary test for the research is Hausman test. 
The present research utilizes Hausman tests to determine which approach is appropriate. The research also went through classical assumption tests in order to increase the validity and reliability of the research. Shapiro-Wilk is using for normality tests, Wooldridge to tests autocorrelation, VIF to detect multicollinearity, and Breusch-Pagan tests to detect heteroskedasticity. These tests are meant to achieve a Best Linear Unbiased Predictor (BLUE) from the Gauss-Markov theory. The successful BLUE test will guarantee the conclusion of the research is highly reliable, and valid.

All data are processed through a single software which is Stata 13. All variables that were selected in this research are converted to codes as mention below:

Table 1. Abbreviation Table

\begin{tabular}{cc}
\hline Variables & Codes \\
\hline Index Output MSME & QOM \\
Regional GDP & QPQDP \\
HDI & HDI \\
Quantity of Microloans & QML \\
Unemployment & QU \\
Inflation & INF \\
\hline
\end{tabular}

Table 2. Statistical Data Summary

\begin{tabular}{cccccc}
\hline Variable & Obs & Mean & Std. Dev. & Min & Max \\
\hline QOM & 96 & 3.916 & 6.146 & $(13.470)$ & 18.880 \\
QPGDP & 96 & $29,000,000.000$ & $43,200,000.000$ & $845,542.000$ & $215,000,000.000$ \\
HDI & 96 & 0.591 & 0.170 & 0.220 & 1.060 \\
QML & 96 & $27,700,000.000$ & $34,200,000.000$ & $(1,432,229.000)$ & $177,000,000.000$ \\
QU & 96 & $(26,989.670)$ & $57,597.920$ & $(308,688.000)$ & $54,991.000$ \\
INF & 96 & 0.010 & 0.027 & $(0.050)$ & 0.068 \\
\hline
\end{tabular}

The table above showed general information on the variables tested in the present research the number of Obs or observations is 96 . These observations came from delta (change) values from the year of 2012-2014. The table above also showed the maximum, minimum value of each of the variables and the standard deviation value.

Table 3. Normality Test Shapiro-Wilk

Shapiro-Wilk Test for 3 parameters log-normal data

\begin{tabular}{|c|c|c|c|c|c|}
\hline Variable & Obs & $\mathrm{W}$ & $\mathrm{V}$ & $\mathrm{Z}$ & Prob $>z$ \\
\hline $\mathrm{QOM}$ & 96 & 0.99161 & 0.669 & -1.251 & 0.8945 \\
\hline QPGDP & 96 & 0.63324 & 29.268 & -1.484 & 0.93106 \\
\hline HDI & 96 & 0.99288 & 0.568 & -0.773 & 0.78033 \\
\hline QML & 96 & 0.72995 & 21.551 & -1.484 & 0.93106 \\
\hline QU & 96 & 0.68989 & 24.748 & -1.484 & 0.93106 \\
\hline INF & 96 & 0.98093 & 1.938 & 1.487 & 0.06848 \\
\hline
\end{tabular}


Table 4. Multicollinearity Test (VIF)

\begin{tabular}{lcl}
\hline Variable & VIF & $1 /$ VIF \\
\hline QOM & 3.44 & 0.290342 \\
QPGDP & 2.66 & 0.375262 \\
HDI & 1.57 & 0.634992 \\
QML & 1.08 & 0.921667 \\
QU & 1.05 & 0.956015 \\
\hline Avg VIF & 1.96 & \\
\hline
\end{tabular}

Each VIF values, and average VIF value $<10$, this implied and concluded that there are no problems regarding multicollinearity. VIF indicated multicollinearity existed from the variance value of each of the variables. VIF will also assess multicollinearity in the overall regression model.

Table 5. Wooldridge Autocorrelation Test

\begin{tabular}{cc}
\hline Wooldridge Test for autocorrelation in Panel Data \\
\hline $\mathrm{F}(1,31)$ & 3.089 \\
Prob > F & 0.089 \\
\hline
\end{tabular}

H0: No First order autocorrelation

H1: First autocorrelation existed

Prob > F Value is > 0.05 alpha therefore no correlation exist. Wooldridge tests are used because it uses fewer assumptions, flexible approach and easier to implement compared to other autocorrelation tests such as Durbin Watsons, \& Baltagi-Wu test.

Table 6. Heteroskedasticity Test (BP-LM \& GLR Method)

\begin{tabular}{lr}
\hline \multicolumn{1}{c}{ Breusch-Pagan Lagrange Multiplier Panel Heteroskedasticity Test } \\
\hline Lagrange Multiplier LM Test & 28.917 \\
Degrees of Freedom & 31 \\
P-Value > Chi2(31) & 0.573 \\
\hline
\end{tabular}

Ho: Panel Homoscedasticity

H1: Panel Heteroskedasticity

Table 7. Greene Likelihood Ratio Panel Heteroskedasticity Test

Greene Likelihood Ratio Panel

Heteroskedasticity Test

\begin{tabular}{cc}
\hline Likelihood Ratio LR Test & 36.028 \\
Degrees of Freedom & 31 \\
P-Value $>$ Chi2(31) & 0.245 \\
\hline
\end{tabular}

Ho: Panel Homoscedasticity

H1: Panel Heteroskedasticity

Both Breusch-Pagan Lagrange Multiplier and Greene Likelihood Ratio test showed P-Value $>0.05$ alpha means that variables are considered to be homogenous. Both tests measure distribution of chi-square and are used for cross-validation. 
Table 7. Hausman Test

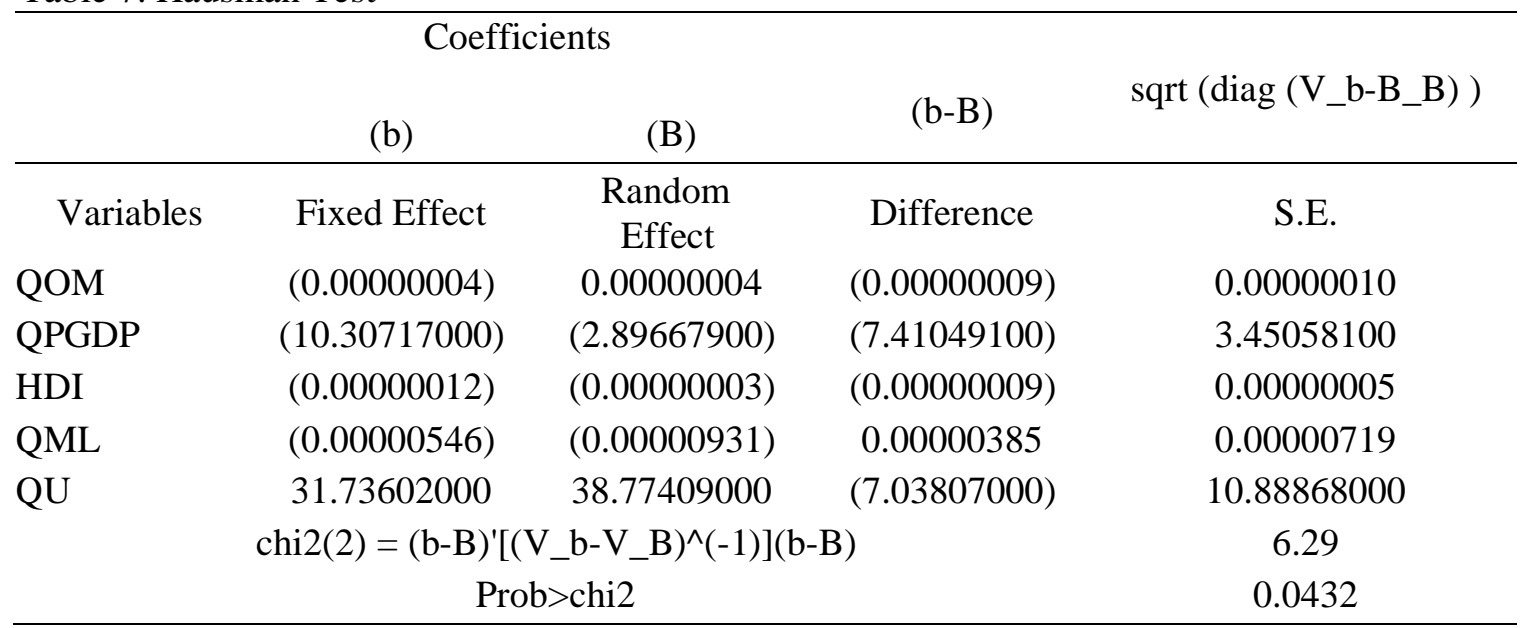

$\mathrm{P}-$ Value $>0.05$ shows that $\mathrm{H} 0$ or null hypothesis can be accepted while the alternative hypothesis will be rejected. If P-Value less than 0.05 means that null hypothesis must be rejected and alternative hypothesis must be accepted. The results show that the P-value is 0.0432 which means that the most appropriate approach is the fixed-effect model.

\section{Result}

The conclusion of the research is shown from the data of $\mathrm{P}>|\mathrm{t}|$ and coefficient value of each independent variable towards the dependent variable. $\mathrm{P}\rangle|\mathrm{t}|$ values presented two variables that are below 0.05 which are HDI, QML.

$$
\mathrm{QOM}=14.191-10.307 \text { HDlit }-0.000000124 \text { QMlit }+e
$$

Table 7. Regression result using fixed effect method

\begin{tabular}{cccccccc}
\hline \multicolumn{7}{c}{ Fixed-effects (within) regression, group variable province } \\
\hline $\begin{array}{c}\text { R-sq Overall } \\
\text { Prob > F }\end{array}$ & 0.0082 & 0.0956 & & & & \\
QOM & Coefficient & Std Error & $\mathrm{t}$ & $\mathrm{P}>|\mathrm{t}|$ & \multicolumn{2}{c}{$95 \%$ Cond. Interval } \\
QPGDP & $-4.21 \mathrm{E}-08$ & $9.87 \mathrm{E}-08$ & -0.43 & 0.671 & $-2.40 \mathrm{E}-07$ & $1.55 \mathrm{E}-07$ \\
HDI & -10.30717 & 5.105303 & -2.02 & 0.048 & -20.52286 & -0.09148 \\
QML & $-1.24 \mathrm{E}-07$ & $5.84 \mathrm{E}-08$ & -2.11 & 0.039 & $-2.40 \mathrm{E}-07$ & $-6.58 \mathrm{E}-09$ \\
QU & $-5.46 \mathrm{E}-06$ & $1.51 \mathrm{E}-05$ & -0.36 & 0.719 & -0.0000357 & $2.48 \mathrm{E}-05$ \\
INF & 31.73602 & 26.07649 & 1.22 & 0.228 & -20.44292 & 83.91495 \\
QOM & 14.19077 & 5.398306 & 2.63 & 0.011 & 3.388787 & 24.99276 \\
\hline
\end{tabular}

The regression model implies that HDI \& QML movement is contradictory towards the development of MSME. Several explanations will influence the recommendation of this research. HDI negatively influences the development of MSME for several reasons. Multiple boundaries existed that affected the growth of young entrepreneurship (Jakubczak, 2015). Firstly it is related to the entrepreneurship culture of Indonesians, and the conditions of the country itself (ILO, 2011). The majority of entrepreneurs in Indonesia have forced entrepreneurs. The economic situation, demanding lifestyle, and low education forces people to become entrepreneurs. These entrepreneurs did not have sufficient resources to work in other places and improve their business.

Secondly educated and middle-high class families planted a stigma to the future generations that the best option is to work for a big corporation while developing a personal business is considered to be risky, and less privilege is available compared to working with large enterprises. Social valuation towards entrepreneurship is a major factor that influences the interests of young generations to enter 
the world of entrepreneurship (Halis et al., 2007).

Thirdly even though the government provided support for the development of MSME, it can be concluded that the assistance is insignificant. MSME growth is slowed down due to the increasing competitiveness of the market. The present MSME also could not compete very well with others and compare to other Asian countries Indonesian MSME is large in number, however, the minimum contribution of exports. Taxes, regulations that existed in the country do not support the significant development of SME (Jakubczak, 2015).

Firstly it is related to the entrepreneurship culture of Indonesians, and the conditions of the country itself (ILO, 2011). The majority of entrepreneurs in Indonesia have forced entrepreneurs. The economic situation, demanding lifestyle, and low education forces people to become entrepreneurs. These entrepreneurs did not have sufficient resources to work in other places and improve their business.

Secondly educated and middle-high class families planted a stigma to the future generations that the best option is to work for a big corporation while developing a personal business is considered to be risky, and less privilege is available compared to working with large enterprises. Social valuation towards entrepreneurship is a major factor that influences the interests of young generations to enter the world of entrepreneurship (Halis et al., 2007).

Thirdly even though the government provided support for the development of MSME, it can be concluded that the assistance is insignificant. MSME growth is slowed down due to the increasing competitiveness of the market. The present MSME also could not compete very well with others and compare to other Asian countries Indonesian MSME is large in number, however, the minimum contribution of exports. Taxes, regulations that existed in the country do not support the significant development of SME (Jakubczak, 2015).

In order to gain a clearer insight, a regression analysis between the significant variables are executed.

Table 8 . The impact of busy commissioners on performance in high and low leverage firms
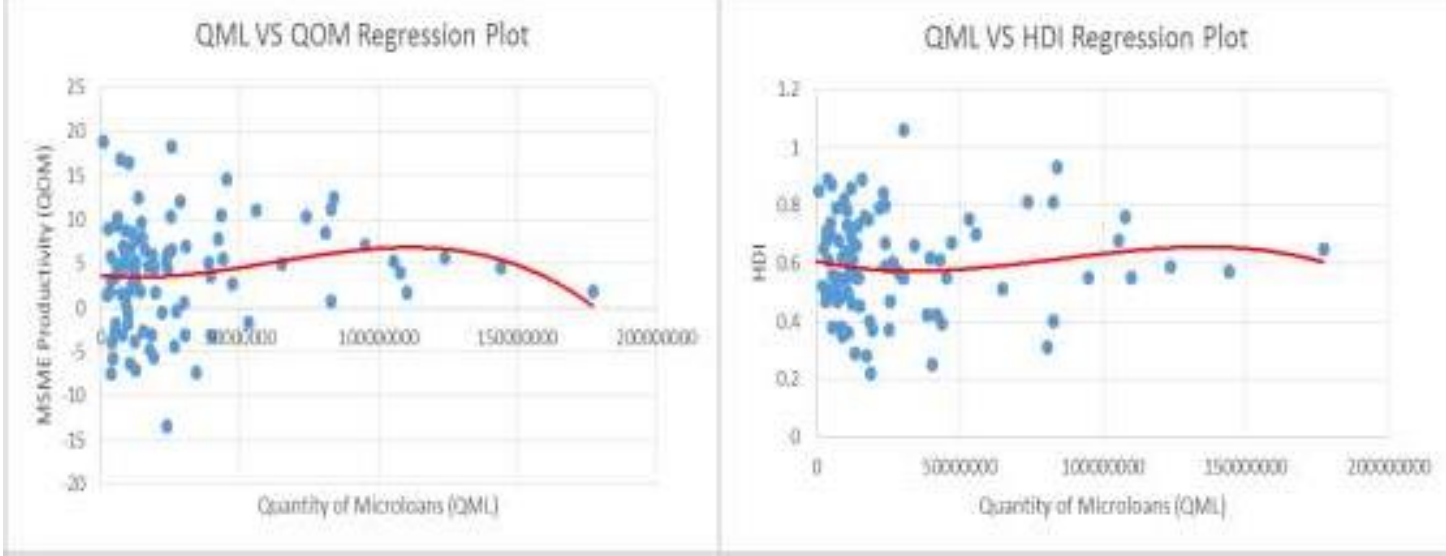

\section{Conclusion}

There are several conclusions that can be gained through the visualization. MSME in Indonesia is currently incompetent to manage larger loans, number of loans will not guarantee productivity, an additional 100,000,000 IDR is the maximum value for a province, in order to maintain an overall positive output. This phenomenon is related to sustainability and quality of MSME condition that is present in the country. There is a limit where the distribution of credit reaches its maximum productivity. The condition caused by the present education system that existed in the country which provided minimum training and growth for the development of MSME. The influence of productivity does not come from the perspective of the quantity of MSME only, quality also matters (GEM, 2017). 


\section{References}

Ademola, A. and Arogundade, K. (2014), "The Impact of Microfinance on Economic Growth in Nigeria", Journal of Emerging Trends in Economics and Management Sciences (JETEMS), pp. 397-405.

Babajide, A. (2012), "Effects of Microfinance on Micro and Small Enterprises (MSEs) Growth in Nigeria", Asian Economic and Social Security, pp. 463-477.

Bateman, M. and Chang, H.-J. (2012), "Microfinance and the Illusion of Development: From Hubris to Nemesis in Thirty Years", World Economic Review, pp. 13-36.

BI. (2015), Profil Bisnis UMKM, Jakarta.

GEM. (2017), Global Entrepreneurship Report.

Gujarati, D.. and Porter, D.C. (2009), Basic Econometrics Fifth Edition, Fifth., McGraw-Hill International Edition.

Halis, M., Ozsabuncuoglu, H. and Ozagir, A. (2007), "The Values of Entrepreneurship and Factors That Effect Entrepreneurship : Findings From Anatolia”, Serbian Journal of Management, Vol. 1, pp. 21-34.

ILO. (2011), Business Environment for Young Entrepreneurs in Indonesia, Jakarta.

Jakubczak, J. (2015), "Youth Entrepreneurship Barriers and Role of Education In Their Overcoming - Pilot Study", Technology, Innovation, and Industrial Management, pp. 1775-1782.

Ledgerwood, J., Earne, J. and Nelson, C. (2013), The New Microfinance Handbook, World Bank, Washington.

Lützenkirchen, C. (2012), "Microfinance in evolution An industry between crisis and advancement", Deutsche Bank Research Management, p. 19.

Michael Troilo, O.B. (2013), "Financing Small and Medium Enterprise in Asia and Pacific", Journal of Entrepreneurship and Public Policy, p. 33.

OECD. (2004), "Promoting Entrepreneurship and Innovative SMEs in a Global Economy, Turkey: Organisation for Economic Co-operation and Development (OECD).", Journal of Microfinance.

Otero, M. (1999), "Bringing Development Bank, into Microfinance", Journal of Microfinance, pp. 8-19.

Pei-Wen, T., Zariyawati, M., Diana-Rose, F. and Annuar, M. (2016), "Impact of Microfinance Facilities on Performance of Small Medium Enterprises in Malaysia”, World Applied Sciences Journal, pp. 1845-1849.

Sharma, G., and Puri, H. (2013), "An Empirical Testing of Relationship Between Microfinance and Economic Growth in India”, Journal of Indian Research, pp. 87-94.

Sutomo, I.D. (2007), "Menjadi Entreprenuer Jempolan (Achieving Entrepreneurial Excellence)", Republika, Jakarta Selatan.

Tambunan, T.T.H. (2011), "Development of Small and Medium Enterprises in a Developing Country The Indonesian Case", Journal of Enterprising Communities: People and Places in the Global Economy, pp. 68-82.

W, V. and Ngugi, D.F.K. (2014), "Effects of Micro-Financing on Growth of Small and Micro Enterprises in Mombasa County.", International Journal of Scientific Engineering and Research (IJSER), pp. 1-5.

Zhuang, et al. (2009), Financial Sector Development, Economic Growth, and Poverty Reduction: A Literature Review, Asian Development Bank, Manila. 